\title{
Perancangan Produk Celana Dalam (Underwear) Pria Jenis Brief dengan Penambahan Joint Menggunakan Metode Quality Function Deployment (QFD)
}

\section{Product Design of Men's Underwear Type Brief with Additional Joint Using Quality Function Deployment (QFD) Method}

\author{
Gidion Karo Karo Gurusinga ${ }^{1 *}$, Ferry Dian Putra Wijaya ${ }^{2}$ \\ ${ }^{1,2}$ Program Studi Teknik Industri, Universitas Bunda Mulia, Jl. Lodan Raya No. 2 Ancol, Jakarta Utara \\ 14430, Indonesia
}

Diterima: 21 Juli 2017; Direvisi:15 November 2017; Disetujui: 20 Januari 2018

\begin{abstract}
ABSTRAK
Penelitian ini membahas modifikasi pakaian dalam pria yang sudah ada di pasaran. Modifikasi tersebut memungkinkan untuk mengubah desain potongan pakaian dalam menjadi bentuk modular. Dalam proses modifikasi, komponen tambahan diperlukan untuk komponen sendi dimana komponen sendi dijahit ke bagian pinggang celana dalam baik kiri maupun kanan. Metode yang digunakan dalam penulisan ini adalah Quality Function Deployment (QFD) dan House of Quality (HOQ). Produk brief yang dimodifikasi diberikan tambahan komponen penyambung berupa hook dan eye-type yang biasa ditemukan pada bra wanita. Penambahan komponen tersebut meningkatkan total harga yang harus dikeluarkan untuk produk yang sudah dimodifikasi sebesar Rp 26.000 per unit.
\end{abstract}

Kata Kunci: Pakaian dalam pria, pakaian dalam, komponen gabungan, Quality Function Deployment (QFD), House of Quality (HOQ)

\begin{abstract}
This paper discussed modification of men's brief underwear which already exists in the market. The modification allowed to change the sectional design of brief underwear into modular form. In the process of modification, the additional component is required for the joint component where the joint component sewed to the waist section of the underwear both left and right. The method would use in this paper are Quality Function Deployment (QFD) and House of Quality (HOQ). Modified products are provided with additional hook and eye-type components, commonly found on women's bra. The additional components increase the total price to be paid for a modified product of $R p$ 26,000 per unit.
\end{abstract}

Keywords: Men's underwear, brief underwear, joining component, Quality Function Deployment (QFD), House of Quality $(H O Q)$

\section{PENDAHULUAN}

\subsection{Latar Belakang}

Berkembangnya sebuah produk seiring waktu ke waktu menjadi semakin cepat prosesnya, hal itu tidak lain disebabkan oleh perkembangan teknologi dan kebutuhan serta keinginan manusia yang semakin meningkat. Produk merupakan apapun yang ditawarkan ke pasar dengan tujuan mendapatkan perhatian, permintaan, pemakaian dan konsumsi yang berkemungkinan dapat memenuhi dan memuaskan kebutuhan dan keinginian (Kotler dan Armstrong, 2016). Sangat penting untuk setiap produk untuk dilakukan pembaharuan, hal ini disebabkan karena setiap produk sendiri memiliki fase hidup. Fase kehidupan pada produk terdapat empat fase, yakini fase pengenalan, fase

"e-mail: gidion@sansico.com 
pertumbuhan, fase kematangan, dan fase kemunduran (Heizer, Render dan Munson, 2017).

Salah satu produk umum dipakai oleh konsumen adalah celana dalam pria. Celana dalam jenis brief dipilih karena merupakan jenis yang paling banyak dipakai oleh konsumen di Indonesia. Namun, pada kondisi tertentu seperti cidera pada kaki, terdapat kesulitan yang dialami dalam pemakaian celana dalam, serta terdapat konsumen yang memiliki ukuran pinggang yang tidak sesuai dengan standar ukuran celana dalam yang dijual dipasaran. Maka dari itu, penelitian ini mendesain celana dalam agar dapat disesuaikan dengan ukuran penggunanya juga memudahkan pemakaiannya dalam pemasangan dan pelepasannya.

Pada penelitian ini menggunakan data sampel karena adanya keterbatasan baik waktu, biaya. Data sampel pada penelitian ini diolah terkait dengan validitas dan reliabelitas.
Salah satu alat untuk membatu dalam proses pengembangan dan perancangan produk adalah Quality Function Deployment (QFD) yang terdapat House of Quality (HOQ) di dalamnya. QFD sendiri memiliki empat fase yaitu fase I (product planning), fase II (product design), fase III (process planning), dan fase IV (production planning) (Mehrjerdi, 2010).

Gambar 1 menampilkan beberapa bagian yang perlu diperhatikan pada HOQ diantaranya (Heizer, Render dan Munson, 2017):

a. Keinginan pelanggan (Voice of Customer/VOC)

b. Bahasa teknis

c. Korelasi antara bahasa teknis

d. Peringkat kepentingan pelanggan

e. Penilaian seberapa baik dalam pemenuhan keinginan pelanggan

f. Penilaian kompetitif

g. Peringkat bobot

h. Nilai target (atribut teknis)

i. Evaluasi teknis

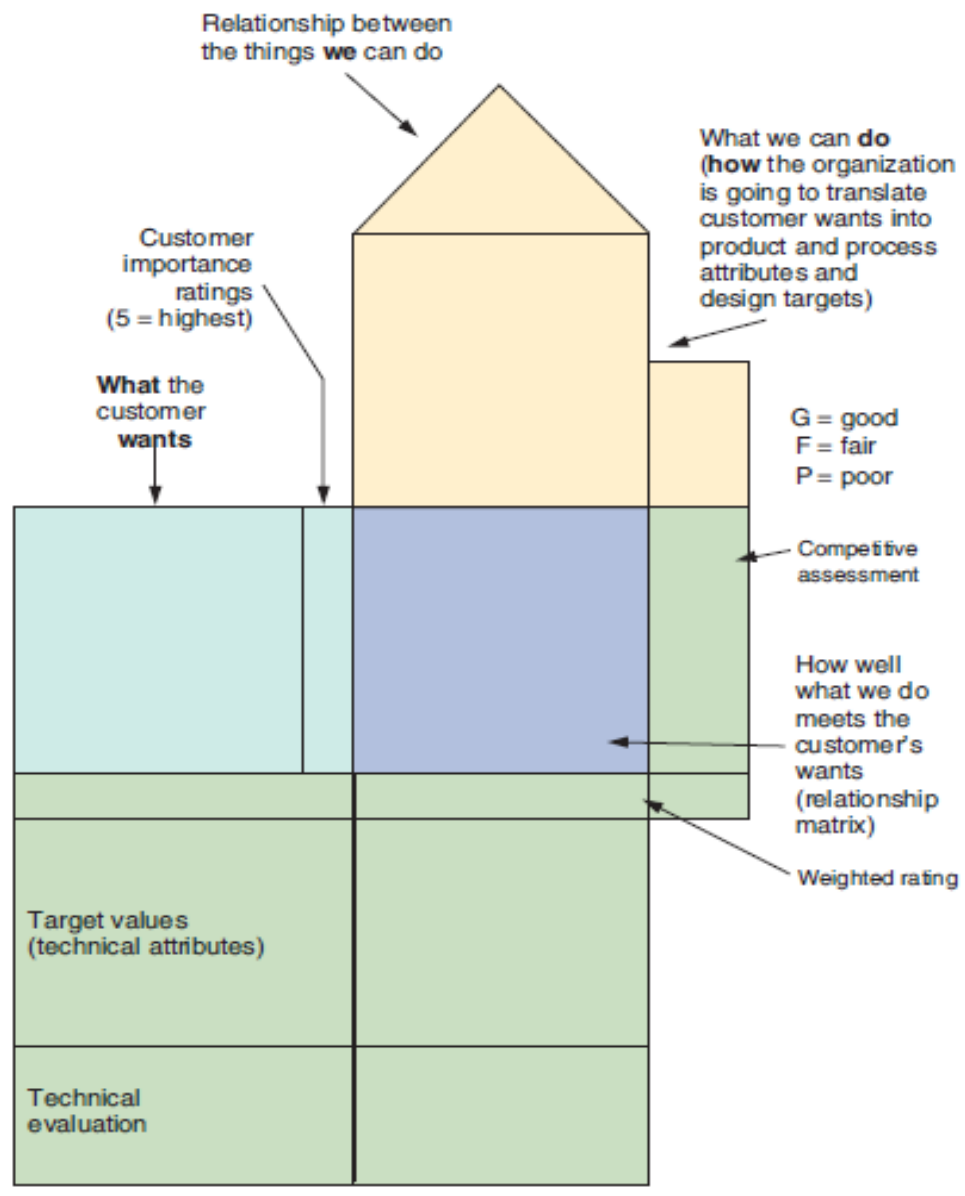

Gambar 1. House of Quality (HOQ) 


\section{METODOLOGI}

Pada penelitian ini dilakukan survei untuk maendapatkan data sampel calon pengguna yaitu konsumen dengan jenis kelamin laki-laki dan berusia di atas 15 tahun. Konsumen dipilih dengan kriteria dengan keccokan produk yang dibuat. Untuk jumlah data responden minimal dapat ditentukan dengan mengalikan jumlah variabel atau pertanyaan dengan minimal 5 kali (Hair et al., 2014). Pada penelitian ini diberikan 5 buah pertanyaan, maka jumlah responeden yang diharuskan jumlahnya pada penelitian ini adalah 25 sampai dengan 50 responden. Pada hasil survei didapatkan 43 responden yang sudah diuji validitas dan reliabillitasnya.

\section{HASIL DAN PEMBAHASAN}

Tabel 1 menampilkan 6 (enam) pertanyaan yang digunakan dalam penelitian ini. Pertanyaan yang diolah untuk pengujian validitas dan reliabilitasnya adalah pertanyaan no. 1 sampai dengan no. 5 , karena pertanyaan tersebut merupakan jenis pilihan ganda yang dapat diberikan peringkat bobot. Bobot yang dimaksud menggunakan skala likert, 1 yang terendah dan 5 yang tertinggi seperti terlihat pada Tabel 2. Khusus untuk pertanyaan no. 6 diolah untuk penentuan peringkat bobot yang ada pada HOQ yang juga merupakan QFD fase I. HOQ dapat dilihat pada Gambar 2. Bobot untuk masalah tertinggi berada pada tingkat kenyamanan, serta produk yang dimodifikasi perlu dievaluasi untuk perencanaan produk agar biaya yang dikeluarkan menjadi lebih rendah. Selain itu juga, penelitian ini memberikan desain gambar pada bahan katun yang dipakai.

Pada QFD fase II diberikan pilihan beberapa komponen tambahan yang dapat digunakan untuk membuat desain brief menjadi bentuk modular. Berikut komponenkomponen yang dapat dijadikan alat penyambung, seperti terlihat pada Gambar 3 sampai Gambar 6.

Tabel 1. Pertanyaan dalam Kuesioner

No. 1

Apakah Anda selalu memakai celana dalam saat tidur?

\begin{tabular}{lc}
\hline Ya, selalu & $\mathrm{O}$ \\
\hline Kadang-kadang & $\mathrm{O}$ \\
\hline Tidak pernah & $\mathrm{O}$ \\
\hline \hline No. 2 & \\
\hline Jenis celana dalam manakah yang bisa Anda pakai dalam aktivitas sehari-hari? & $\mathrm{O}$ \\
\hline (Jika ada lebih dari satu jenis celana dalam yang Anda gunkan, pilihlah yang paling sering Anda pakai) \\
\hline Boxer Brief & $\mathrm{O}$ \\
\hline Brief & $\mathrm{O}$ \\
\hline Boxer & $\mathrm{O}$ \\
\hline Thong & $\mathrm{O}$ \\
\hline Jockstrap & $\mathrm{O}$ \\
\hline Bikini & $\mathrm{O}$ \\
\hline Trunk & \\
\hline \hline No. 3 & \\
\hline Berapa besar biaya yang Anda keluarkan untuk pembelian celana dalam? & $\mathrm{O}$ \\
\hline Rp 35,000 & $\mathrm{O}$ \\
\hline$>$ Rp 50,000 & $\mathrm{O}$ \\
\hline
\end{tabular}

No. 4

Jenis kuantitas berapakah yang biasa Anda beli?

1 Kemasan berisi 3 buah

1 Kemasan berisi 2 buah

1 Kemasan berisi 1 buah

No. 5

Dengan apakah Anda biasa mencuci celana dalam Anda?

Mesin cuci 
Dengan tangan

$\mathrm{O}$

Menggunakan jasa laundry

$\mathrm{O}$

No. 6

Apa sajakah masalah yang ada pada celana dalam yang biasa Anda gunakan?

Harga yang tergolong mahal

Tidak sesuai dengan ukuran (biasa kelonggaran atau kesempitan)

Material bahan yang terasa panas

Material bahan yang tidak nyaman pada bagian selangkangan

Desain yang kurang menarik

Warna yang cepat pudar

Lainnya

Tabel 2. Pertanyaan dalam Kuesioner dalam Skala Likert

\section{No Pertanyaan}

$1 \quad$ Apakah Anda selalu memakai celana dalam saat tidur?

Ya, Selalu $\quad 5$
3

Kadang-Kadang

3

Tidak Pernah

2 Jenis selana dalam manakah yang biasa Anda pakai?

Brief

Boxer

Boxer Brief

Bikini

Trunk

Jockstrap

Thong

3 Berapa besar biaya yang biasa anda keluarkan untuk membeli celana dalam?

$<35 \mathrm{rb}$

$35 \mathrm{rb}-50 \mathrm{rb}$

$50 \mathrm{rb}$

5

Jenis kuantitas berapakah yang biasa anda pilih

1 kotak berisi 3 buah

1 kotak berisi 2 buah

1

1 kotak berisi 1 buah

Dengan apakah anda biasa mencuci celana dalam anda?

mesin cuci

dengan tangan

menggunkan jasa laundry 


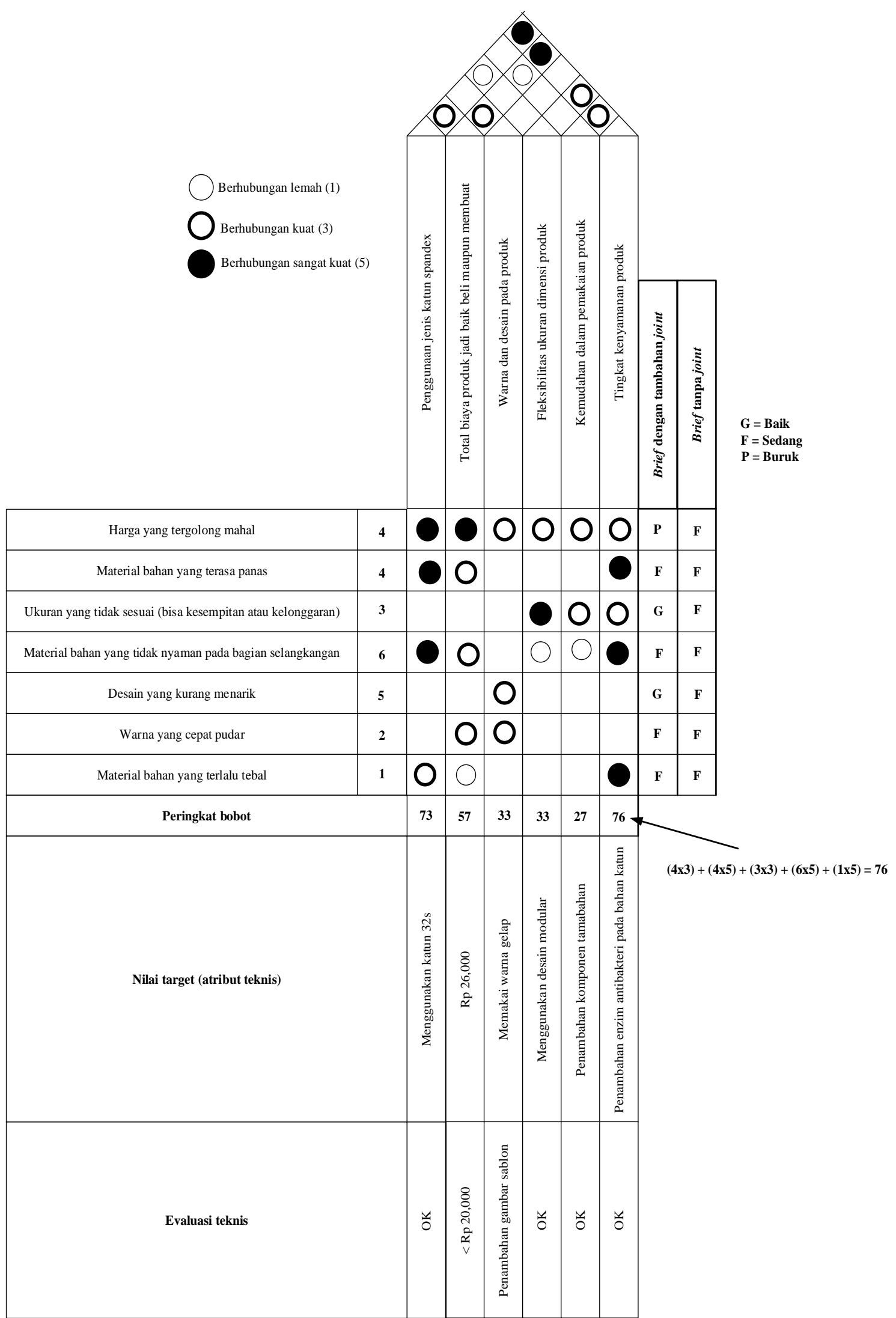

Gambar 2. House of Quality (HOQ) 


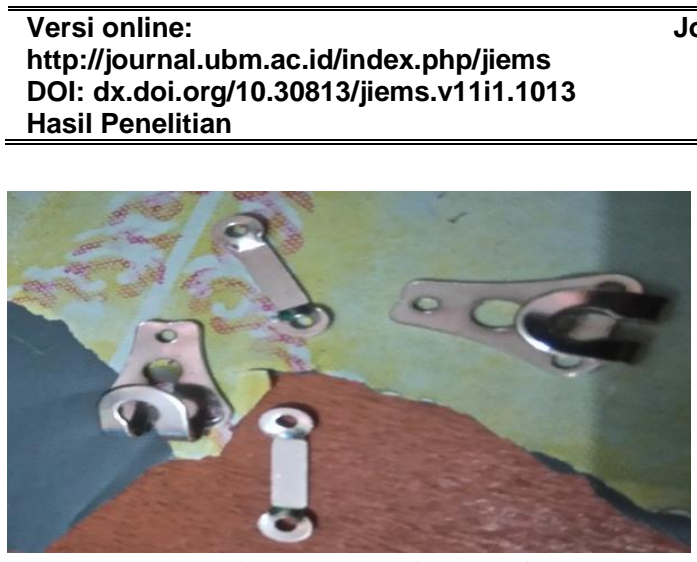

Gambar 3. Kancing Jepit

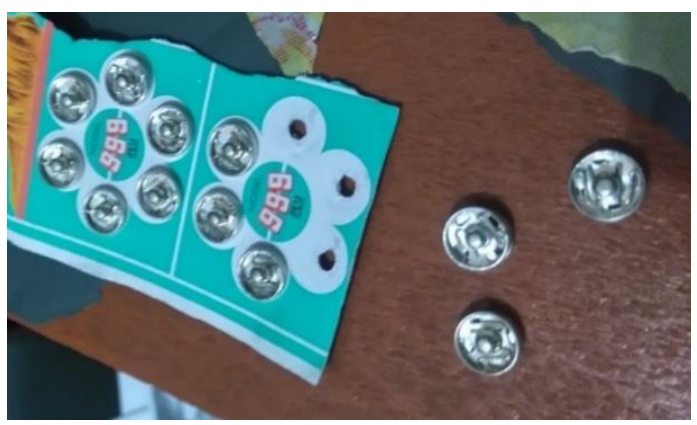

Gambar 4. Kancing Jepret

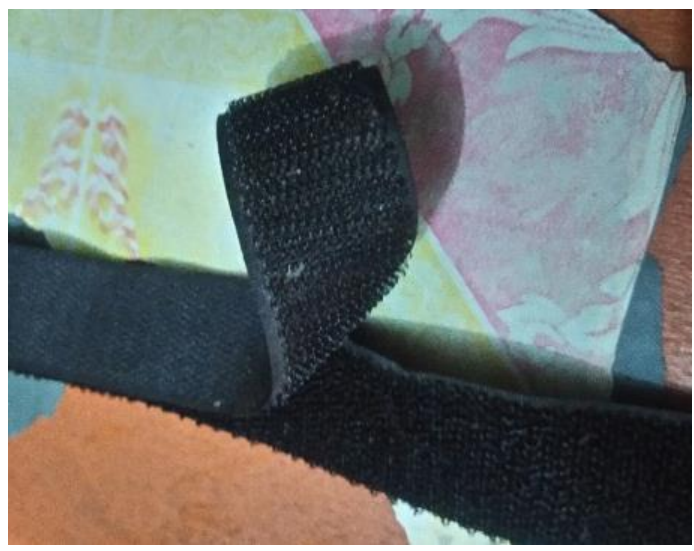

Gambar 5. Strap Perekat

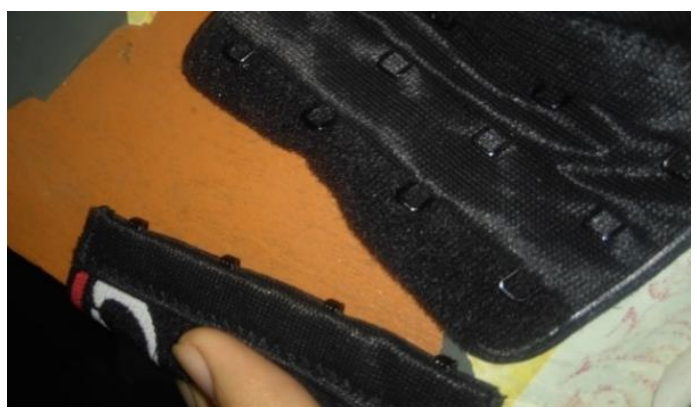

Gambar 6. Hook dan Eye-type

Pada QFD fase III, dilakukan pemilihan dari keempat komponen untuk dijadikan komponen penyambung pada bagian kanan kiri pinggang brief. Komponen yang terpilih adalah hook dan eye-type dengan harga $\mathrm{Rp} 14.000$ untuk 2 pasang
Journal of Industrial Engineering and Management Systems

Vol. 11, No. 1, 25-31, 2018

ISSN 1979-1720

E-ISSN 2579-8154

komponen dan Rp 1000 untuk ongkos pemasangan.

Gambar 7 menunjukkan sketsa produk brief, sedangkan Gambar 8 menunjukkan hasil pengembangan produk.. Pada sketsa produk brief yang ditambahkan hook dan eyetype sebagai komponen penyambung, dengan satuan sentimeter. Produk brief yang dipakai adalah brief yang sudah ada dipasaraan dengan merek SOREX dan didapatkan dengan harga Rp 11.000 per buah.

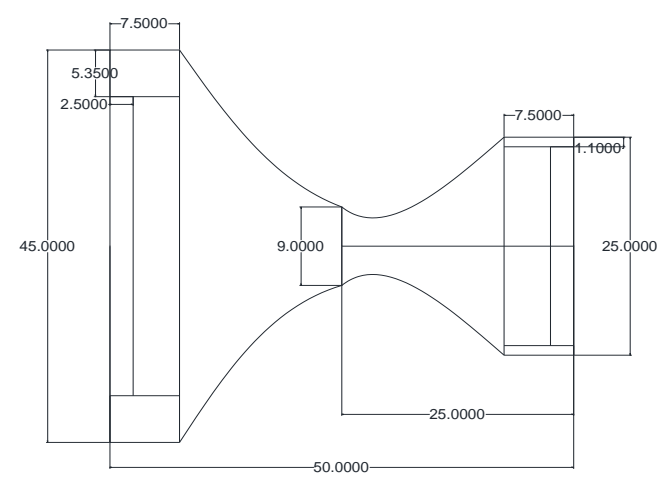

Gambar 7. Sketsa Produk Brief

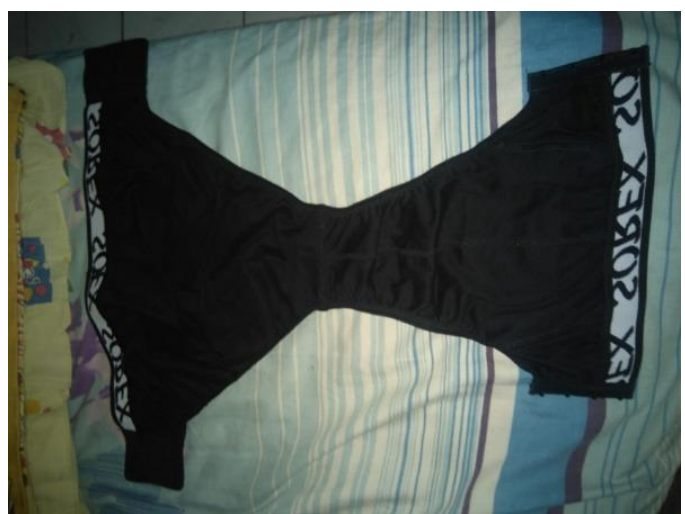

Gambar 8. Hasil Pengembangan Produk

Pada QFD fase IV diberlakukan evaluasi untuk perencanaan produksi selanjutnya, dimana produk yang dibuat harus direncanakan untuk penurunan harganya dengan target dibawah Rp 20.000 yang sebelumnya $\mathrm{Rp} 26.000$ dan juga penambahan motif sablon pada bahan katun spandex katun yang digunakan guna menambah daya tarik desain. 


\section{KESIMPULAN}

Produk brief yang dimodifikasi diberikan tambahan komponen penyambung berupa hook dan eye-type yang biasa pada bra wanita. Jenis brief yang dipilih merupakan brief yang sudah ada dipasaran dengan merek SOREX yang didapatkan dengan harga $\mathrm{Rp}$
11.000. Penambahan komponen tersebut menyebabkan total harga yang harus dikeluarkan untuk produk yang sudah dimodifikasi sebesar Rp 26.000 per unit. Berdasarkan HOQ prioritas tertinggi yang dipilih konsumen dalam pembelian celana dalam adalah dari aspek kenyamanan.

\section{DAFTAR PUSTAKA}

Hair, J. F. et al. (2014) Multivariate Data Analysis. 7 ed. London: Pearson Education Limited.

Heizer, J., Render, B. dan Munson, C. (2017) Operations Management: Sustainability and Supply Chain Management. 12 ed. New York: Pearson Education.

Kotler, P. dan Armstrong, G. (2016) Principles of Marketing. 16 ed. London: Pearson Education Limited.

Mehrjerdi, Y. Z. (2010) "Quality Function Deployment and Its Extensions," International Journal of Quality and Reliability Management, 27(6), hal. 616-640. doi: 10.1108/02656711011054524. 